\title{
Clinical and biological particularities of depressive disorder in women patients
}

\author{
Gavril Radu, Gavril Mihaela Raluca, Dobrin Irina, \\ Traian Carmen, Ștefănescu Cristinel
}

\begin{abstract}
Radu Gavril - MD, Resident in psychiatry, Socola Institute of Psychiatry Iași
Raluca Mihaela Gavril - PhD student, psychiatrist, Socola Institute of Psychiatry Iași Irina Dobrin - MD, PhD, lecturer, psychiatrist, Grigore T. Popa University of Medicine and Pharmacy Iași

Carmen Traian - Specialist Clinical Psychologist, Socola Institute of Psychiatry Iași

Cristinel Ștefanescu - MD, PhD, professor, psychiatrist, Grigore T. Popa University of Medicine and Pharmacy Iași
\end{abstract}

\begin{abstract}
Even though the modern age has offered multiple progress both technological and medical and that includes life expectancy, a series of issues have been noticed within the lifestyle that negatively affects mental health. Although acute depressive disorder is one of the most frequent and invalidating psychiatric disorders from modern times, its origin remains unclear. The prevalence of this disorder has increased in the past 3 decades. Even though this may be caused by errors in diagnostic procedures and later release of patients, it is most probable that there are modern factors that contribute to this increase. Together with the physiopathological mechanisms that involve the role of cerebral monoamines in depression, the inflammatory hypothesis according to which there is a bi-directional relation between depression and inflammation, seems to get more support in the scientific world. Even though there were noted differences both between the clinical chart and the evolution of the depressive disorder in men and women and this is a very important aspect that needs to be considered in the clinical approach of the patient, each being an unique case.
\end{abstract}

\section{KEY WORDS:}

Depressive disorder, cerebral monoamines, inflammatory hypothesis.

\section{INTODUCTION}

A major depressive disorder is one of the most frequent and invalidating psychiatric disorders. Although its etiology remains unclear (1). A meta-analysis that included articles from 1995 to 2016 made clear the connection between different biological and psychological models. Some possible histopathological mechanisms of depression 
ryor include modified neurotransmission, the melancholic

predisposition is anomalies of the hypothalamic-hipofizopredominant. Daily fluctuations in adrenal axes implicated in chronic stress, inflammation, reduced neuroplasticity, and neuronal network dysfunctions. All these proposed mechanisms are tied and interact bidirectionally. Besides, it has been proved that psychiatric stress factors have a direct effect over neuro-development, determining a biological predisposition to depression, while biological factors may lead to psychiatric pathology. Authors suggest that even though there are different phenotypes of depression with different fiziopathological mechanisms, it can be useful that depression is considered to be a single syndrome, in which these mechanisms interact as different nods in a matrix (2).

Numerous studies suggest universal and substantial a women preponderance in depression. There are taken into consideration all the possible hypotheses in this type of phenomenon and the contribution of changing sex roles, social factors, and biological factors are analyzed. While these factors lead to some type of contribution, it has been concluded that it exists a higher biological factor, such as stress receptivity or hyperactivity of the limbic system, that mainly contributes to differentiating of the genre in some expressions of depression and anxiety as well and reflects the impact of gonadal steroids at puberty modification $(3,4)$.

It has been noted that there are differences between the clinical aspect as well as the evolution in recurrent depressive disorder in men and women. Depression in women develops at a younger age, the number of recurrences is higher and the remission periods are longer. Even though, the complete remission is obtained more frequently in men. The most common symptom associated with depression in women is anxiety, while in men disposition, suicidal thoughts are predominant in women, according to a study made bu Ivanets and collaborators (5). Fatigability and the reduction of motivation are most frequent in men. Selfguilt, social isolation, adinamy, permanent fatigue sensation are most frequent in women. Sleep disorders are just as frequent in men and women, but sleep architecture disorders are most frequent in women (6). Somatic symptoms associated with depression are generally more frequent in men, as well as cardiovascular co-morbidities, respiratory, and genital-urinary (7). Men have a greater risk of ethanolic abuse and other psychoactive substances in the attempt of managing the symptoms (8).

Depression symptoms are an epidemic problem that affects different subgroups of women in different environments (9). Even though the depressive symptoms of working women have been rarely studied. In a study made bu Al-Monadall and collaborators, the depressive symptoms and its determinant factors were studied on a 101 working women control group in Jordan, that was recruited in an institution of superior studies. Data about the depressive symptoms of the women were collected, as well as their educational level, the presence of offspring, the sharing of the working place with an intimate partner, the health state, the chronic disease diagnostic, and the husband abuse. The results illustrated that $51.2 \%$ of the women complained of moderate and severe depressive symptoms. The indicated factors classed as important in the prediction of the depressive symptoms were the women's experience with abuse from husbands and chronicle disease diagnostic. A conclusion has been reached according to which the causes of depressive symptoms in women have been classified in the social and 
family environment, instead of the working place. (10).

In a community study made in 2009 in Malaysia, 480 women were evaluated to establish the prevalence and the associated factors with the depressive disorder. Information was collected about the variables in socio-demographic factors, high-risk potential factors (family history and mental health problems, depressive symptoms in life, and associated stress factors), and actual depressive symptoms. Out of the risk factors, the most common risk was the history of depressive manifestations, followed bu actual life stress factors and family history of mental illness. Among the socio-demographic variables used, the health state perceived was of the utmost importance (11). The associated factors with symptoms of depression were found in this study under the discoveries in the Occident, which implies a universality of the phenomenon and the tied factors of the symptoms of depression in women (12). The prevalence of the depression symptoms reported by the study was comparable with the anterior studies $(13,14)$.

The anxiety and depression symptomatology of the adult has to do with numerous factors, that put their stamp over the perspective of life ever since childhood. We are talking here about the family patter, the lifestyle filled with stress and abuse, the family pathological incidence, alcohol consumption, and psychoactive substances (15). Even though, no anterior study has evaluated the mediator role of smoking in association with childhood adversity, anxiety, and depressive symptoms in adult age. Even more, the importance of the variables that confront with the mediator response was rarely demonstrated empirically in psychiatric and social epidemiology. (16).
A representative study, that implicated 4570 people that have as a purpose the evaluation of the role of smoking in adult age in association with the childhood adversity in anxiety and depressive symptoms at adult age and the evaluation of the estimated factors that integrate with the mediator answer (education, alcohol consumption, and social support) (17). Childhood adversity has been associated with a $10 \%$ risk factor in adolescence smoking and 9\% in adult life when education was excluded as a variable confused with the mediator response the indirect effect of childhood adversity over the depressive and anxiety symptoms of adult life have been statistically significative. This study shows the inclusion of potential variables integrated is important in the evaluation of the mediation (18).

Daily basses issues and environment, for instance, urbanization and exposure to noise and chemical pollution and human interface are in a decrease in rapport with the technology that contributes also to the incidence and maintenance of depression. There are necessary studies that exploit the modification of the lifestyle that implicates more elements in the lifestyle (19). While the abusive and incorrect use of medicine and psychological techniques are often blamed, because of the complexity of the disease it is encouraged a more integrative approach of depression and admittance of the fact that the modification of the lifestyle should be a part of the treatment and prevention (20). The children exposed to social adversity, present a higher risk to mental health and physical health in adult life. It is believed that this higher risk is because of the inflammatory process associated with childhood adversity it contributes to many etiological diseases in adults. 
Social adversity in the prenatal period is a risk factor for high inflammation at adult age independent of the adversities of the childhood period. This proof is following the studies that prove the adverse exposure to the maternal environment while gestation has a longer effect on immunity system development (21). If these results reflect a causal association this suggests that the intervention for improving the social conditions and pregnancy environment to promote health to the overall life. It remains necessary for the identification of the mechanisms that link maternal conditions during pregnancy from fetal immunity development and other systems involved in the adaptation of the stress factors (22).

Numerous studies on animals have proven that the systemic or central administration of proinflammatory cytokine induces similar symptomatology with the equivalent of the depressive symptoms in humans. The human population that suffers from inflammatory Cronic diseases like type 2 diabetes, rheumatoid arthritis, cardiovascular diseases have reported increased incidents of depressive disorders. Moreover, the studies measure the terrific expression of cytokines in human patients with depression that have indicated that pro-inflammatory cytokines levels such as alpha tumoral necrose factor, 1 beta interleukin, and 6 interleukins are significantly increased in this clinical population in comparison with the control groups (23). Few studies investigated the inflammatory phenomenon at the brain level in the context of depression and suicidal behavior. Independent groups have reported proof of increased expression of proinflammatory cytokines in cortical regions involved in depression and suicide. How central and peripheric inflammatory phenomenon links to depression and suicide is a good question and needs to be more investigated. (24).

There is a link between immunity function and psychiatric conditions, especially in depressive and anxiety disorders. Psychological stress is a high factor for this kind of disorder and stress. As it was already been demonstrated influences immunity (25). The basolateral amygdala is indispensable for emotion and plays an important role in stress effects on anxiety. Therefore it can be the main mediator of the central nervous system for peripheric immune modification effects on anxiety after stress (26).

The epidemiologic data regarding the prevalence of mood disorders demonstrates that major depressive disorder is approximately twice as frequent in females than in males and usually starts in females who have the reproductive function active (27). To efficiently treat depression in women and to prevent the apparition of the disorder clinicians must understand the specific aspects of feminine gender and mood disorders within the reproduction part of the lifetime in women. Therefore, a biopsychosocial approach should be the primary objective of future practice and research, to result in an integrated etiological model of depression in women. Based on the prevalence of depressive disorder in women, screening, intervention, and diagnostic at the appropriate time should be a priority in public health (28).

\section{MATERIALS AND METHODS}

To evaluate the relationship between inflammation, the intensity of depression somatic and psychiatric comorbidities associated, a retrospective study has been done, comparing statistical analysis, that targets female patients committed in Clinic nr. 5 of the Psychiatric Institute Socola, in 2018, 
(1) with major depressive disorder diagnostic. RESULTS

The demographic data were analyzed, the intensity of depression has been measured through the Hamilton depression scale, VSH values, and suicidal associated risk. From the total number of selected patients, a subgroup of patients has extracted that presented suicidal risk.

The groups of patients who have been selected from the electronic archive of the Socola Institute of Psychiatry and consulting the clinical documents the patients expressed the consent for the usage of personal data in the use of scientific research. The statistical use of data was done in excel and established a correlation between the intensity of depression through the HAMD score and VSH value. Also, it has been used the function of linear regression and statistical analysis ANOVA for highlighting the presence of a significant $\mathrm{p}$, the margin of error being 0.05 .

The valoric, graphic, and percentual analysis followed mainly the VSH values in ascending order, according to the age standards: women group with age between 20-40 years and 4160 years with VSH $>20$ and women $>61$ with $\mathrm{VSH}<30$. Age groups represent the second element in classification. For each patient is being registered the degree of depression (HAMD scale) and anxiety level (HAMA scale), these values being presented for each age group from the moment of being committed, the depression value (HAMD) being considered severe.

Tabel 1. Report male/female committed between 20102018

\begin{tabular}{|l|l|l|l|l|}
\hline Year & $\begin{array}{l}\text { Total of } \\
\text { patients }\end{array}$ & Women & Male & $\begin{array}{l}\text { Women } \\
\text { with } \\
\text { suicidal } \\
\text { risk }\end{array}$ \\
\hline $\mathbf{2 0 1 0}$ & 198 & $93(47 \%)$ & $\begin{array}{l}105 \\
(53 \%)\end{array}$ & 22 \\
\hline $\mathbf{2 0 1 8}$ & 156 & $67(49 \%)$ & $\begin{array}{l}89 \\
(51 \%)\end{array}$ & 15 \\
\hline
\end{tabular}

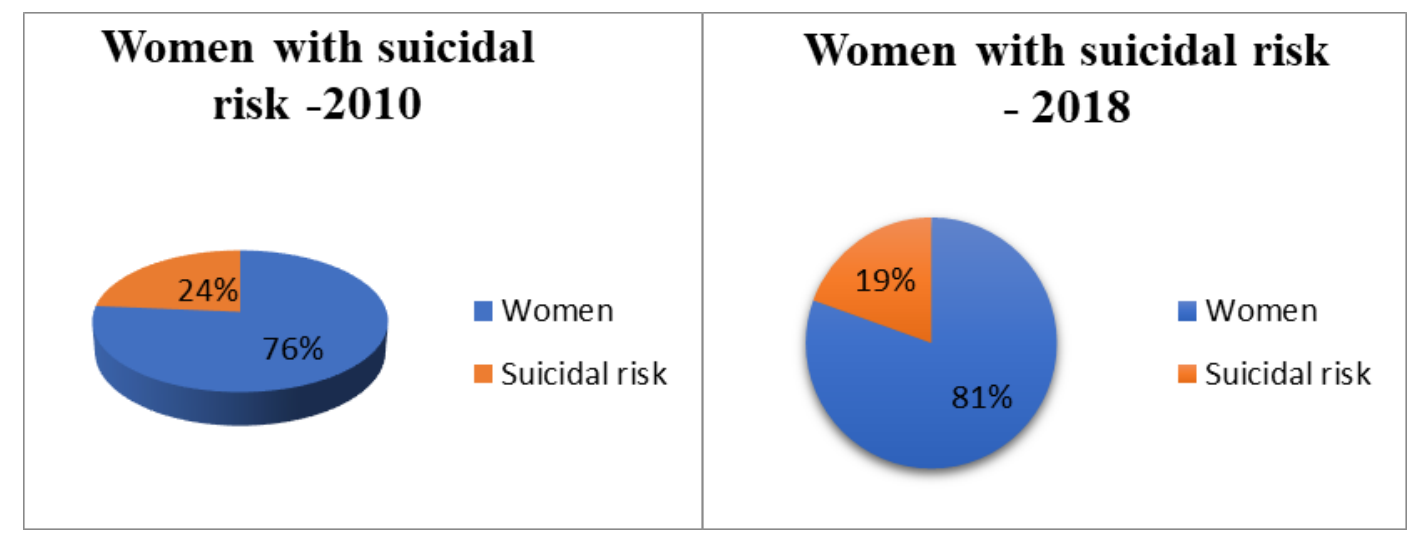

Fig. 1 Report of females committed between 2010-2018

Analyzing the above data we observe the fact that there are no major differences between the number of women and men that have been committed both in 2010 and 2018 the numeric and percentage tendency is higher in men. In $201053 \%$ of the patients are men, over $47 \%$ of women, and in $201851 \%$ are men and $49 \%$ are women.
Regarding patients that have a suicidal risk, it has been noted that there is a diminishing percentage from $24 \%$ out of the total number of women committed in 2010 and $19 \%$ in 2018.

Regarding the environment for the patients committed in 2010 and 2018, the differences are very small, 43 women from the rural 
56/Bulletin of Integrative Psychiatry ONew Series O September 2020 ○ Year XXVI ONo. 3 (86)

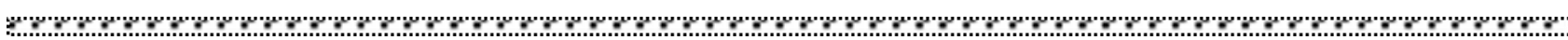
environment and 50 women from the urban rural environment and 35 from urban environment, and in 201832 women from the provenience.

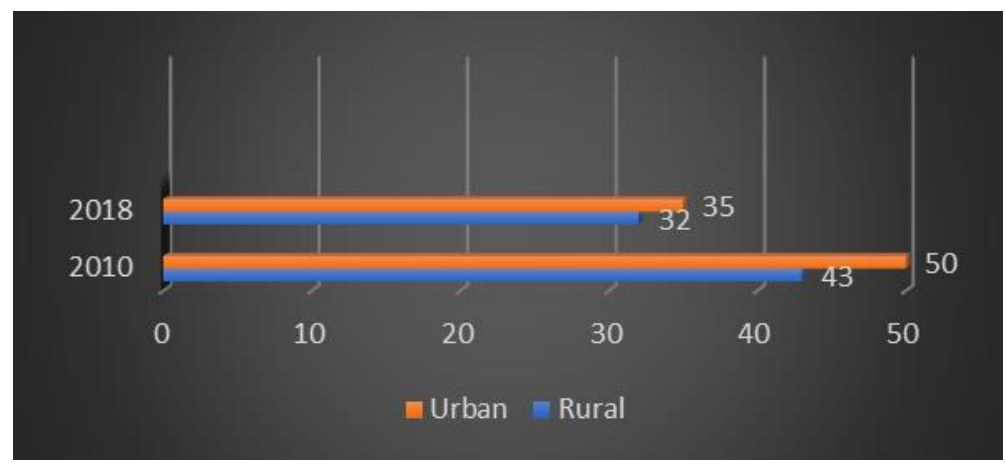

Fig. 2 The origin environment of the patients

The environment doesn't represent an exact variable that influences in a big measure the actual study, considering that the tendency of the population to move from city centers to the outskirts of cities and nearby villages, therefore cannot be classified by the hospital archive, as from rural provenience.

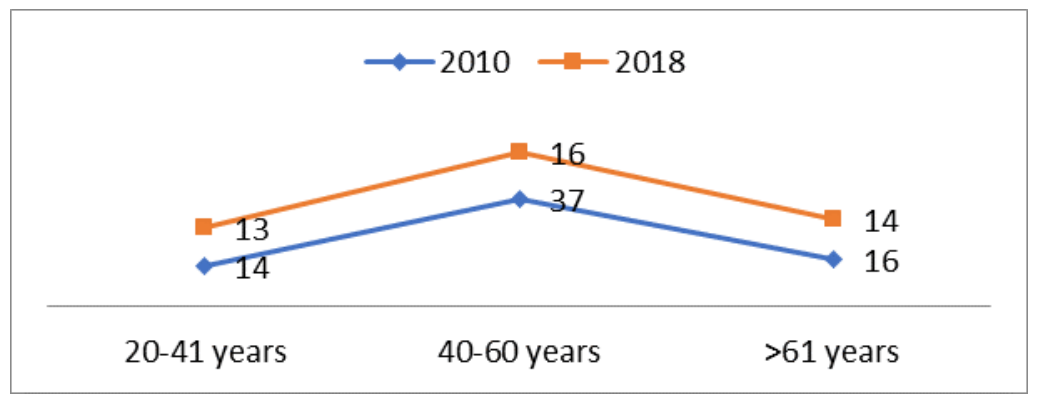

Fig. 3 Distribution by age groups

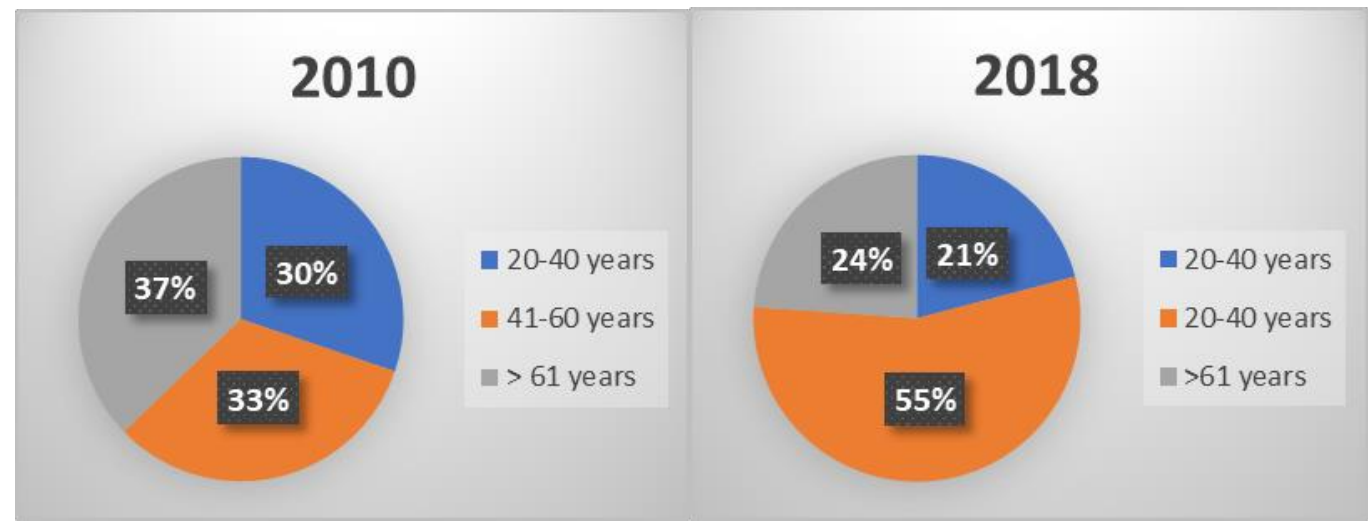

Fig. 4 Repartition of patients according to age groups in 2010 vs 2018

In regarding the distribution depending on age groups, it has been noted that in 2010 as well as in 2018 the fact that the majority of patients are with ages between 41-60 have a significant increase in depression from a groupage 40-60 (from 30\% in 2010 to $55 \%$ in 2018) and a decrease in the number of patients with ages over 61 (from 37\% in 2010 to $24 \%$ in 2018 ). 
Bulletin of Integrative Psychiatry O New Series OSeptember 2020 ○ Year XXVI ONo. 3 (86)/57

s

The application of the Hamilton scale for patients with depression in the study revealed scores with less than 27 points and patients that do not have 25 scores were not included in the study. The average of the scores in depression in 2018 for women registered a HAMD value of $32.04 \pm 2.23$, in HAMA case $26.3 \pm 1.33$ with a VSH value of $19.17 \pm 8.17$. Following the same parameters in 2010, the average score for depression calculated with the HAMD scale in women in 2010 with the average value for HAMD was $31,14 \pm 2,56$, for HAMA - 25,51 $\pm 1,46$ and an average value for VSH of $22,25 \pm 6,76$.

To identify and study the relationship between VSH and HAMD from the women study group without suicidal thoughts in 2010 was calculated the PEARSON coefficient $\mathrm{r}=0,6 \mathrm{~m}$ value that suggests a moderate correlation between the 2 variables. The positive sign suggests that the low score from the first variable correlates with the low score of the second variable. The average score from the first variable correlates with the average score from the second variable. The higher score from the first variable correlates with the higher score from the second variable. To find out the $\mathrm{p}$-value it has been applied the linear regression function in EXCEL. The statistical analysis ANOVA observers the HAMD values and VSH $\mathrm{F}(1,20)=0,5$, at a $\mathrm{p} 0,5$.

\begin{tabular}{|l|l|l|}
\hline $\begin{array}{l}\text { Regression } \\
\text { Statistics }\end{array}$ & Column 1 & \\
\hline Multiple R & 0.783553718 & \\
\hline R Square & 0.613956429 & \\
\hline $\begin{array}{l}\text { Adjusted R } \\
\text { Square }\end{array}$ & 0.59465425 & \\
\hline $\begin{array}{l}\text { Standard } \\
\text { Error }\end{array}$ & 2.121950008 & \\
\hline Observations & 22 & \\
\hline
\end{tabular}

\begin{tabular}{|l|l|l|l|l|l|}
\hline ANOVA & & & & & \\
\hline & $d f$ & $S S$ & $M S$ & $F$ & Significance $F$ \\
\hline Regression & 1 & 143.2192905 & 143.2193 & 31.807 & $1.60915 \mathrm{E}-05$ \\
\hline Residual & 20 & 90.05343676 & 4.502672 & & \\
\hline Total & 21 & 233.2727273 & & & \\
\hline
\end{tabular}

\begin{tabular}{|l|l|l|l|l|l|l|}
\hline Column 1 & Coefficients & Standard Error & t Stat & P-value & Lower 95\% & Upper 95.0\% \\
\hline Intercept & 21.8448610 & 1.887858266 & 11.5712 & $2.58 \mathrm{E}-10$ & 17.906857 & 25.78286436 \\
\hline VSH & 0.41198017 & 0.0730484 & 5.63982 & $1.61 \mathrm{E}-05$ & 0.2596038 & 0.564356469 \\
\hline
\end{tabular}

Similarly we evaluated the group of patients without suicidal thoughts in 2018. The PEARSON coefficient $r-0,52$ suggesting a strong correlation between VSH and HAMD. Statistical analysis ANOVA indicates $\mathrm{F}(1,47)=0,9$ at a $\mathrm{p}=0,9$.

\begin{tabular}{|l|l|}
\hline Regression Statistics & \\
\hline Multiple R & 0.726697 \\
\hline R Square & 0.528089 \\
\hline Adjusted R Square & 0.518048 \\
\hline Standard Error & 1.467662 \\
\hline Observations & 49 \\
\hline
\end{tabular}

\begin{tabular}{|l|l|l|l|l|l|}
\hline ANOVA & & & & & \\
\hline & $D f$ & $S S$ & $M S$ & $F$ & Significance $F$ \\
\hline Regression & 1 & 113.2912 & 113.291 & 52.5949 & $3.39 \mathrm{E}-09$ \\
\hline Residual & 47 & 101.2395 & 2.154031 & & \\
\hline Total & 48 & 214.5306 & & & \\
\hline
\end{tabular}


58/Bulletin of Integrative Psychiatry ONew Series O September 2020 ○ Year XXVI ONo. 3 (86)

\begin{tabular}{|l|l|l|l|l|l|l|l|}
\hline & Coefficients & $\begin{array}{l}\text { Standard } \\
\text { Error }\end{array}$ & $t$ Stat & P-value & $\begin{array}{l}\text { Lower } \\
95 \%\end{array}$ & $\begin{array}{l}\text { Lower } \\
95.0 \%\end{array}$ & Upper 95.0\% \\
\hline Intercept & 28.2468 & 0.529814 & 53.314 & $1.08 \mathrm{E}-43$ & 27.18 & 27.181 & 29.31269 \\
\hline VSH & 0.20128 & 0.027755 & 7.2522 & $3.39 \mathrm{E}-09$ & 0.145 & 0.1454 & 0.257122 \\
\hline
\end{tabular}

As we observe in the above graphic the highest values of $\mathrm{VSH}$ are associated with higher values in HAMD, sustaining the hypothesis that inflammation and depression are in a bidirectional relationship.
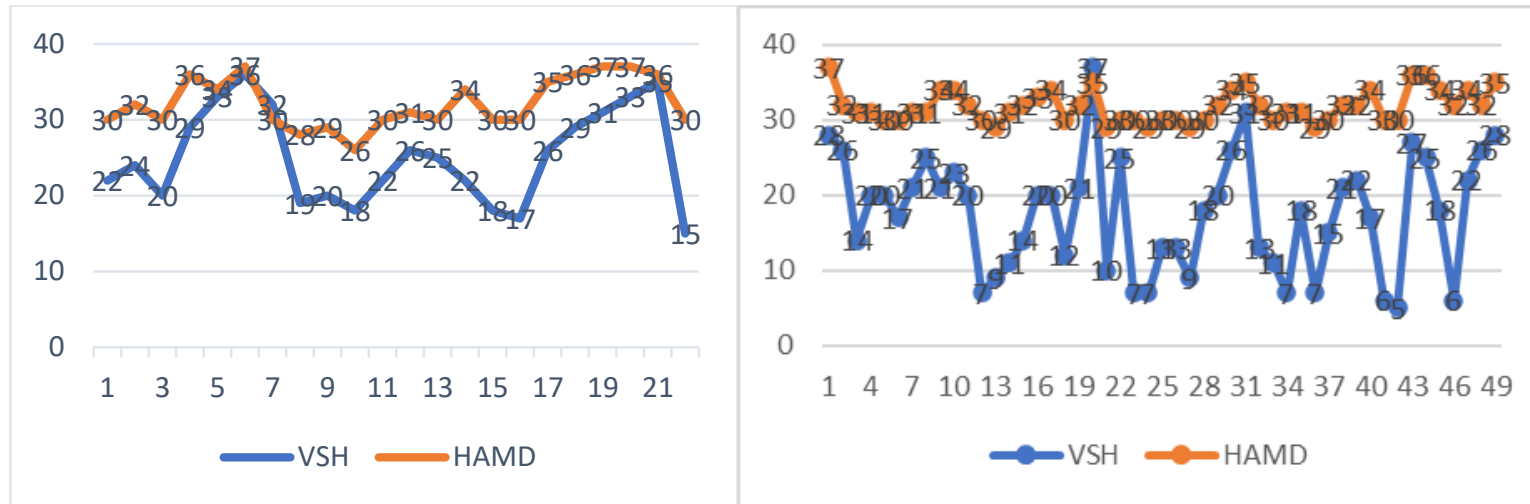

Fig. 5 Correlations VSH-HAMD in patients

Without suicidal thoughts in 2010-2018

\begin{tabular}{|l|l|}
\hline Regression Statistics & Column 1 \\
\hline Multiple R & 0.2071492 \\
\hline R Square & 0.0429108 \\
\hline Adjusted R Square & 0.0368467 \\
\hline Standard Error & 2.4942093 \\
\hline Observations & 14 \\
\hline
\end{tabular}

We analyzed the women group with suicidal risk in 2017. For the 14 patients we identified an average value of HAMD score $33 \pm$ for standard deviation 2.44 an average value of VSH of 24,9 \pm deviation standard 7,57 and for HAMA an average value $26,37 \pm$ deviation standard 1,3 .

\begin{tabular}{|l|l|l|l|}
\hline & VSH & HAMD & HAMA \\
\hline Media & 24.928571 & 33 & 26.375 \\
\hline Dev. St. & 7.5799765 & 2.44 & 1.30247 \\
\hline
\end{tabular}

The Pearson coefficient $r=0,04$, a value that suggests a moderate correlation between the two variables. To find out the $\mathrm{p}$-value it has been applied to the linear regression function in Excel, the significant threshold chosen was $<0,05$. We can observe the ANOVA statistical analysis between the HAMD and VSH $\mathrm{F}(1,12)=0,5$ values at $\mathrm{p} 0,1$.

\begin{tabular}{|l|l|l|l|l|l|}
\hline & & & & & \\
\hline Column1 & Coefficients & Standard Error & t Stat & P-value & \\
\hline Intercept & 31.331261 & 2.3706983 & 13.21605 & $1.64 \mathrm{E}-08$ & \\
\hline VSH & 0.0669408 & 0.0912627 & 0.733496 & 0.477342 & \\
\hline ANOVA & & & & & \\
\hline & $D f$ & $S S$ & $M S$ & $F$ & Significance F \\
\hline Regression & 1 & 3.34704 & 3.34704 & 0.538016 & 0.477342 \\
\hline Residual & 12 & 74.65296 & 6.22108 & & \\
\hline Total & 13 & 78 & & & \\
\hline
\end{tabular}


Bulletin of Integrative Psychiatry O New Series OSeptember 2020 ○ Year XXVI ONo. 3 (86)/59 s s Similarly, we analyzed the women group with The statistical analysis continues to suicidal risk from the year 2010 and identified a HAMD average value of $32.181 \pm 3,33$ standard deviation with an average VSH value of $25,090 \pm 6,33$ standard deviation with an average HAMA value of $25,545 \pm$ 1,47 standard deviation.

Also, the Person coefficient has been calculated with an $\mathrm{r}=0,61$, witch suggests a evidentiate a $\mathrm{p}=0,5$ significant statistic.

strong correlation between HAMD value and VSH value.

\begin{tabular}{|l|l|l|l|l|l|}
\hline & $D f$ & $S S$ & $M S$ & $F$ & Significance F \\
\hline Regression & 1 & 143.2192905 & 143.219 & 31.8076 & $1.60915 \mathrm{E}-05$ \\
\hline Residual & 20 & 90.05343676 & 4.50267 & & \\
\hline Total & 21 & 233.2727273 & & & \\
\hline Column1 & Coefficients & Standard Error & $\boldsymbol{t}$ Stat & $\boldsymbol{P}$-value \\
\hline Intercept & 21.8448610 & 1.887858266 & 11.5712 & $2.58 \mathrm{E}-10$ \\
\hline VSH & 0.41198017 & 0.0730484 & 5.63982 & $1.61 \mathrm{E}-05$ \\
\hline
\end{tabular}

As it is indicated in the graphical representation from above in female cases with suicidal risk selected in 2010 and 2018,

\begin{tabular}{|l|l|}
\hline Regression Statistics & Column1 \\
\hline Multiple R & 0.78355371 \\
\hline R Square & 0.61395642 \\
\hline Adjusted R Square & 0.59465425 \\
\hline Standard Error & 2.12195000 \\
\hline Observations & 22 \\
\hline
\end{tabular}

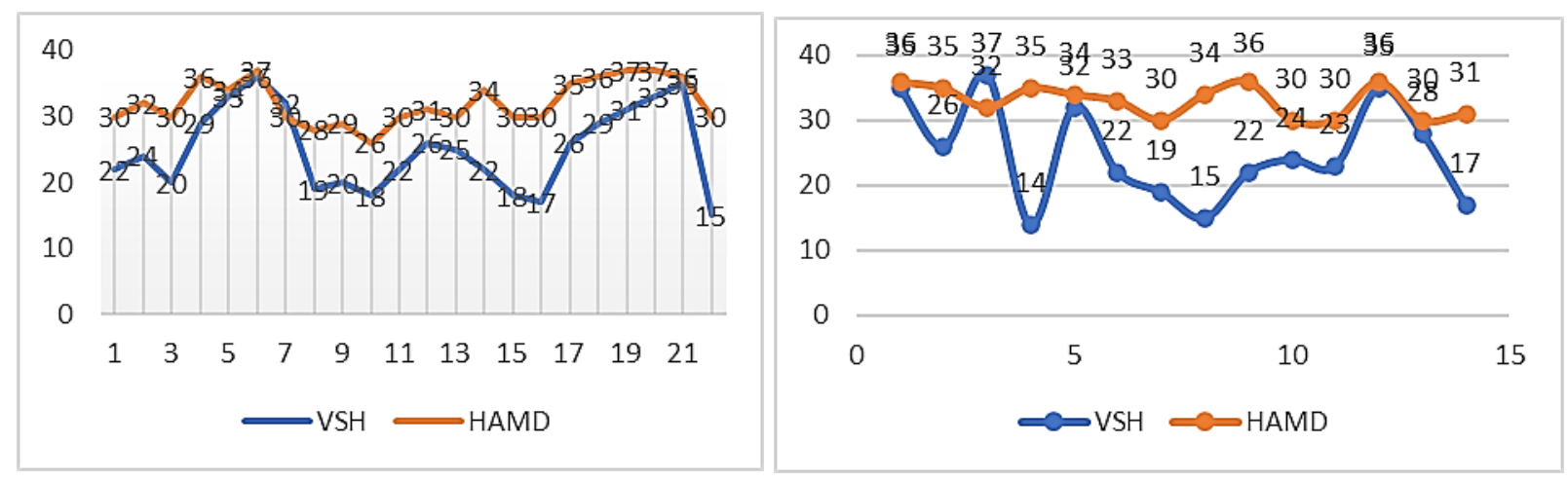

Fig. 6 Correlations VSH-HAMD in patients with suicidal thoughts in 2010-2018

\section{CONCLUSIONS}

Although the etiology of depression and the inflammatory hypothesis are subjects that need to be investigated furthermore we can conclude that between inflammation and depression there is an important link.

We noticed that in patients with suicidal thoughts the correlation between increased values of HAMD score and increased VSH value is stronger than in patients with depression without suicidal thoughts.

Analyzing the demographical data we did not see particularities between women with depression. In 2010 as well as in 2018 the distribution was the same using the parameter origin environment. 


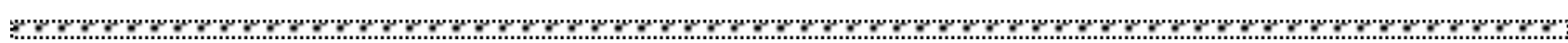
If in 2010 the patient's repartition depending on groupage did not note a significant difference in 2018 we see an important increase in the number of patients age between 40-60 and a diminishing in the number of patients with age over 60 .

\section{ACKNOWLEDGEMENTS AND DISCLOSURES}

The authors have no potential conflict of interests to disclose.

\section{REFERENCES}

1. Peretti S, Judge R, Hindmarch I. Safety and tolerability considerations: tricyclic antidepressants vs. selective serotonin reuptake inhibitors. Acta Psychiatr Scand Suppl. 2000.

2. Jason D, Keshaven M, The neurobiology of depression: An integrated view, Asian Journal of Psychiatry. 2017;27:101-111.

3. Parker G, Brotchie H, Gender differences in depression, Int Rev Psychiatry.2010;22(5):429-36.

4. Ioannidis JP. Effectiveness of antidepressants: an evidence myth constructed from a thousand randomized trials? Philos Ethics Humanit Med. 2008.

5. Ivanets $\mathrm{N}$, Tyuvina $\mathrm{N}$, Voronina $\mathrm{O}$, Balbanova $\mathrm{V}$, Comparative evaluation of depressive disorders in women and men, Zh Nevrol Psikhiatr Im S S Korsakov. 2018;118(11):15-19

6. Park L, Zarate C, Depression in primary care setting, N Engl J Med. 2019;380(6):559-568.

7. Gavin NI, Gaynes BN, Lohr KN, Meltzer-Brody S, Gartlehner G, Swinson T. Perinatal depression: a systematic review of prevalence and incidence. Obstet Gynecol. 2005;106:1071-83.

8. Talge NM, Neal C, Glover V. The early stress, translational research, and prevention science network: fetal and neonatal experience on child and adolescent mental health. Antenatal maternal stress and long-term effects on child neurodevelopment: how and why? J Child Psychol Psychiatry. 2007;48:245-61.

9. Elghossain T, Bott S, Akik C, Obermeyer CM., Prevalence of intimate partner violence against women in the Arab world: a systematic review., BMC Int Health Hum Rights. 2019;19(1):29. doi: 10.1186/s12914-019-0215-5

10. H Al-Modallal, J Abuidhail, A Sowan, A Al-Rawashdeh, Determinants of depressive symptoms in Jordanian working women, J Psychiatr Ment Health Nurs. 2010;17(7):569-76.

11. Meriam Omar Din ${ }^{1}$, Noraini M Noor, Prevalence, and factors associated with depressive symptoms in Malay women, Women Health. 2009;49(8):573-91.

12. Cheah YK, Azahadi M, Phang SN, Abd Manaf NH. Sociodemographic, Lifestyle, and Health Factors Associated With Depression and Generalized Anxiety Disorder Among Malaysian Adults. J Prim Care Community Health. 2020;11:2150132720921738. doi:10.1177/2150132720921738.

13. Sheikh MA. Confounding and Statistical Significance of Indirect Effects: Childhood Adversity, Education, Smoking, and Anxious and Depressive Symptomatology. Front Psychol. 2017;8:1317.

14. Slopen N, Loucks EB, Appleton AA, et al. Early origins of inflammation: An examination of prenatal and childhood social adversity in a prospective cohort study. Psychoneuroendocrinology.2015;51:403-413. doi:10.1016/j.psyneuen.2014.10.016

15. Agerup T., Lydersen S., Wallander J., Sund A. M. Maternal and paternal psychosocial risk factors for clinical depression in a Norwegian community sample of adolescents. Nord. J. Psychiatry 2015;69:35-41. 10.3109/08039488.2014.919021.

16. Albers A. B., Biener L.The role of smoking and rebelliousness in the development of depressive symptoms among a cohort of Massachusetts adolescents. Prev. Med.2002;34, 625-631.

17. Sheikh MA. Confounding and Statistical Significance of Indirect Effects: Childhood Adversity, Education, Smoking, and Anxious and Depressive Symptomatology. Front Psychol. 2017;8:1317.

18. Baldassari A. R., Cleveland R. J., Callahan L. F. Independent influences of current and childhood socioeconomic status on health outcomes in a North Carolina family practice sample of arthritis patients. Arthritis Care Res. (Hoboken). 2013;65: 1334-1342.

19. Jimenez MP, Wellenius GA, Subramanian SV, et al. Longitudinal associations of neighborhood socioeconomic status with cardiovascular risk factors: A 46-year follow-up study. Soc Sci Med. 2019;241:112574. doi:10.1016/j.socscimed.2019.112574 
20. Steiner J, Bielau H, Brisch R et al. Immunological aspects in the neurobiology of suicide: elevated microglial density in schizophrenia and depression is associated with suicide. J Psychiatr Res. 2008;42:151-157.

21. Pandey GN, Rizavi HS, Ren X, Fareed J, Hoppensteadt DA, Roberts RC, et al. Proinflammatory cytokines in the prefrontal cortex of teenage suicide victims. J Psychiatr Res.2012;46:57-63. doi:10.1016/j.jpsychires.2011.08.006

22. Howren MB, Lamkin DM, Suls J. Associations of depression with C-reactive protein, IL-1, and IL-6: a metaanalysis. Psychosom Med.2009; 71:171-86.

23. Slopen N, Loucks EB, Appleton AA, et al. Early origins of inflammation: An examination of prenatal and childhood social adversity in a prospective cohort study. Psychoneuroendocrinology.2015;51:403-413.

24. Rau AR, Chappell AM, Butler TR, Ariwodola OJ, Weiner JL. Increased Basolateral Amygdala Pyramidal Cell Excitability May Contribute to the Anxiogenic Phenotype Induced by Chronic Early-Life Stress. J Neurosci. 2015;35(26):9730-9740.

25. Jimenez MP, Wellenius GA, Subramanian SV, et al. Longitudinal associations of neighborhood socioeconomic status with cardiovascular risk factors: A 46-year follow-up study. Soc Sci Med. 2019;241:112574.

26. De Guingand DL, Palmer KR, Snow RJ, Davies-Tuck ML, Ellery SJ. Risk of Adverse Outcomes in Females Taking Oral Creatine Monohydrate: A Systematic Review and Meta-Analysis. Nutrients. 2020;12(6):1780.

27. Van der Waerden JE, Hoefnagels C, Hosman CM. Psychosocial preventive interventions to reduce depressive symptoms in low-SES women at risk: a meta-analysis. J Affect Disord. 2011;128(1-2):10-23.

28. Hagerty BM. Advances in understanding major depressive disorder. J Psychosoc Nurs Ment Health Serv. 1995;33(11):27-34.

Correspondence:

Raluca Mihaela Gavril,

PhD student, psychiatrist, Socola Institute of Psychiatry Iasi, gavrilradu25@gmail.com

Submission: 2 aug 2020

Acceptance: 4 sep 2020 